\title{
V. An experimental essay on salt as a manure, and as a condiment mixed with the food of animals
}

\section{Rev. Edmund Cartwright}

To cite this article: Rev. Edmund Cartwright (1805) V. An experimental essay on salt as a manure, and as a condiment mixed with the food of animals, Philosophical Magazine Series 1 , 23:89, 16-26, DOI: $10.1080 / 14786440508562475$

To link to this article: http://dx.doi.org/10.1080/14786440508562475

曲 Published online: 18 May 2009.

Submit your article to this journal \lceil

Џ Article views: 2

Q View related articles $\square$ 


\section{[ 16 ]}

Y. An experimental Essay on Salt as a Manure, and as a Condiment mixed with the Food of Animals. By the Rev. Edmund Cartwright, of Woburn*.

W ERE the beneficial effects of salt as a manure to be once fairly ascertained, there can be no doubt but the wisdom of the legislature would devise some means by which, without prejudice to the revenue, the farmer might apply it to the purposes of agriculture.

At present the use of salt as a manure is a subject on which the public opinion is much divided: its advocates, reasoning from the striking effects of salt water on the marshes which are occasionally irrigated by the sea at spring tides, conclude that the fertilizitig virtue of such irrigation is owing to its saline quality, without taking into consideration the quantity of animal and vegetable matter which sea water (particularly near the coast, and where rivers disembogue themselves) must necessarily hold in solution.

Those who maintain a contrary opinion, considering salt merely as an antiseptic, satisfy themselves that it is impossible that any thing can be friendly to vegetation which retards putrefaction; a process indispensable in substances that are to be the food of plants. To get over this difficulty, it has been conjectured, nay, there have not been wanting those (and of great name too) who have even attempted to prove, that salt in small quantities accelerates, as in large quantities it is known to resist, putrefaction; a doctrine to which, however, I shall not willingly yield my assent, till I can be persuaded that effects are not, in all cases, proportionate to their causes. The operation of every cause is, and must be, uniform; and when, to appearance, it is not so, some other cause obtrudes itself, too subtile for our observation, which, operating at the same time with the primary cause, joins in giving a result, which not being able to account for, we consider as anomalous.

That theorists should be at variance with each other is not to be wondered at; for, having the wide field of imagination and conjecture before them to expatiate in, it is reasonable to conclude, indeed it is unavoidable, that some of them must lose their way. But what shall we say to the disagreement and inconsistency which prevail on this sub-

* From the Cummunications to the Board of Agriculture, which adjudged to the author the gold medal for this essay. 
ject amongst practical farmers? Nothing, indeed, can be more contradictory than the different reports that have been made on the effects of salt, as a manure, by those who have even brought it to the test of actual experiment. As there is no reason to question the veracity of the reporters, we must look for the grounds of their disagreement in some predominating circumstance or other, which at the time escaped their observation. Indcal, the success or failure of an agricultural experiment depends so frequently on causes which can neither be controlled nor foreseen, and so foreign from those which were expected to operate, that it is not to be wondered at if the repetition of the very same experiment gives oftentimes a different result.

As it is not the business of this paper to support a theory, but to detail what has been practised; not to contend for an opinion, but to state facts ; the few oliservations which may be hazarded will be such only as are required merely in explanation of occurrences as they arise. I shatl endeavour to give, therefore, as simple a relation as possible of the experiments I have tried, to ascertain the advantages or disadvantages which may attend the use of salt as a manure, and also when mixed with the food of animals.

Jt may be necessary, first of all, to premise, that the soil on which my experiments were tried is a ferruginous sand, brought to a due texture and consistence by a liberal covering of pond mud. Of this soil, in its improved state I mean, by the accession of pond mud (for, having been used merely as a nursery for raising forest trees previous to these experiments, the nursery-man had not thotght it necessary to make use of any other manure), the following is the analysis :

400 grains gave of siliceous sand of different degrees of fineness about

Grains.

of finely divided matter, which appeared in the form of clay

Loss in water

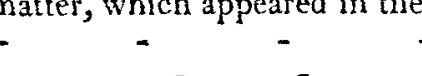

The 104 grains of finely divided matter contained of carbonate of lime

Of oxide of iron

Loss by incineration (most probably from vegetable decomposing matter) The remainder principally silex and alumine. Yol. 23. No, 89. Oct. 1805. B 
There were no indications of either gypsum or phosphate of lime.

It will appear from the above analysis that these experiments could not perhaps have been tried on a soil better adapted to give impartial results ; for of its component parts there is no ingredient (the oxide of iron possibly excepted) of sufficient activity to augment or restrain the peculiar energies of the substances employed.

On the 14th of April 1804, a certain portion of this soil was laid out in beds one yard wide and forty long. Of these, twenty-five were manured (the first excepted) as follows :

No. 1. No manure.

2. Salt, $\frac{1}{4}$ peck.

3. Lime, one bushel.

4. Soot, one peck.

5. Wood-ashes, two pecks.

6. Saw-dust, three bushels.

7. Malt-dust, two pecks.

8. Peat, three bushels.

9. Decayed leaves, three bushels.

10. Fresh dung, three bushels.

11. Chandler's graves, nine pounds:

12. Salt, lime.

13. Salt, lime, sulphuric acid.

14. Salt, lime, peat.

15. Salt, lime, dung.

16. Salt, lime, gypsum, peat.

17. Salt, soot.

18. Salt, wood-ashes.

19. Salt, saw-dust.

20. Salt, malt-dust.

21. Salt, peat.

22. Salt, peat, bone-dust.

23. Salt, decayed leaves.

2*. Salt, peat-ashes.

25. Salt, chandler's graves.

N. B. The quantities of each ingredient the same as when used singly.

On the same day the whole was planted with potatoes, a single row in each bed; and, that the general experiment might be conducted with all possible accuracy, each bed received the same number of sets.

On the 14th of May, a few days after the plants appeared above ground, the whole was carefully examined, and the comparative excellence of each row (as far at least as could be judged of by appearances) was as carefully registered. 
gistered. The best row was decidedly No. 7, malt-dust, after which they followed as under:

No. 11. Chandler's graves.

16. Salt, lime, gypsum, peat.

25. Salt, graves.

20. Salt, malt-dust.

9. Decayed leaves.

4. Soot.

2. Salt.

1. No manure.

5. Wood-ashes.

8. Peat.

13. Salt, lime, sulphuric acid.

14. Salt, lime, peat.

17. Salt, soot.

18. Salt, wood-ashes.

21. Salt, peat.

22. Salt, peat, bòne-dust.

23. Salt, decayed leaves.

3. Lime.

6. Saw-dust.

10. Fresh dung.

12. Salt, lime.

15. Salt, lime, dung.

24. Salt, peat-ashes.

19. Salt, saw-dust.

On the 28th of May, fourteen days afterwards, the apparent vigour of the plants was in the following order.

No. 7. Malt-dust.

11. Chandler's graves.

4. Soot.

8. Peat.

16. Salt, lime, gypsum, peat.

17. Salt, soot.

20. Salt, malt-dust.

21. Salt, peat.

23. Salt, decayed leaves.

25. Salt, graves.

1. No manure.

2. Salt.

5. Wood-ashes.

9. Decayed leaves.

13. Salt, lime, sulphuric acid.

14. Salt, lime, peat.

18. Salt, wood-ashes.

21. Salt, peat-ashes. 
10. Fresh dung.

3. Lime.

22. Salt, peat, bone-dust.

19. Salt, saw-dust.

15. Salt, lime, dung.

12. Salt, lime.

6. Saw-dust.

On the 21 st of September the potatoes were taken up, when the produce of each row was in succession as follows :

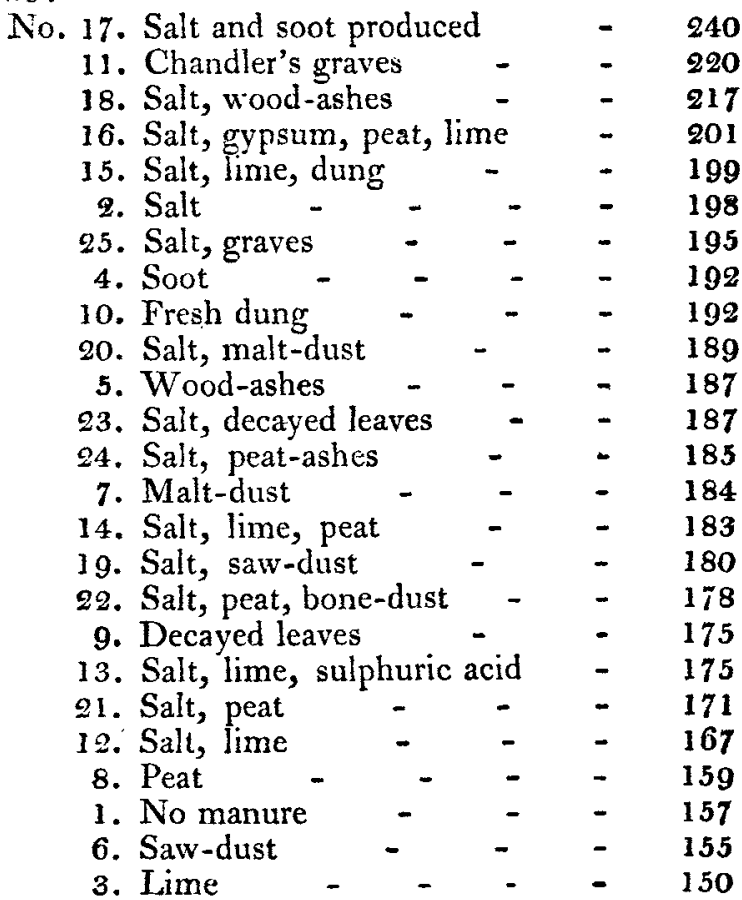

The foregoing table furnishes many particulars worthy of observation. In the first place it is remarkable, that of ten different manures, most of which are of known and acknowledged efficacy, salt, a manure hitherto of an ambiguous character, is superior to them all, one only excepted! And again, when used in combination with other substances, it is only unsuccessfully applied in union with that one, namely, chandler's graves, no other manure seemingly being injured by it. Possibly its deteriorating effects on chandler's graves may be owing to its antiseptic property, which retards the putrefactive process by which 
animal substances undergo the changes necessary to qualify them to become the food of plants. This, however, I cannot, from any appearance in the soil when the plants were taken up, assert to have been the case.

The extraordinary effects of salt, when combined with soot, are strikingly singular. There is no reason to suppose these effects were produced by any kuown chemical agency of soot or salt on each other. Were I to guess at the producing cause, I should conjecture it to be that property of saline substances by which they attract. moisture from the atmosphere; for I observed those beds where salt had been used were visibly and palpably moister than the rest, even for weeks after the salt had been applied; and this appearance continued till rain fell, when of course the distinction ceased. This property of attracting moisture had greater influence possibly on the soot than on any of the other manures, as soot, from its acrid and dry nature, may be supposed to require a greater proportion of water to dilute it than those substances which contain water already. It may be proper to observe, that on those beds' where salt had been used the plants were obviously of a paler green than on the rest, though not less luxuriant; a circumstance which I thought worth noticing, and which I considered, though erroneously (as appeared by the event), to indicate a want of vigour, which would be felt in the crop. It was observable also, that where salt was applied, whether by itself, or in combination, the roots were free from that scabbiness which oftentimes infects potatoes, and from which none of the other beds (and there were in the field nearly forty more than what made part of these experiments) were altogether exempt.

Two sets of experiments, and with the same proportions of manures, were tried with turnips and buck-wheat, on a soil the poorest I could meet with, which produced only a dwarf heath and lichen, and which I had had pared off. The poverty of this soil will appear by the following analysis :

Grains.

400 grains gave of siliceous sand $\quad-\quad$ - 320

Of finely divided matter, which appeared as brown

mould - $\quad-\quad-6 \quad-68$

Loss in water $\quad-\quad+\quad-\quad$ - 12

The finely divided matter lost by incineration nearly half B 3 
its weight; which shows it contained a great deal of veretable matter. The residuum principally a mixture of aluminous and siliceous earths, coloured red by oxide of iron, and containing very little calcareous matter. There were no indications of either gypsum or phosphate of lime.

July 6,1804 , the pieces set apart for each set of experiments were respectively sown with turnips and buck-wheat.

On the 26 th, Nos. 1, 2, 4, 5, 6, 7, 19, 20, 21, 22, 24,25 , showed little or no marks of vegetation. The remainder were merely in the seed-leaf.

On the 16th of August four only were alive, and in rough leaf, namely,

No. 32. Salt and lime.

13. Salt, lime, and sulphuric acid.

14. Salt, lime, peat.

16. Salt, lime, gypsum, peat.

These four maintained a sickly existence till the middle of September; shortly after which they all disappeared.N. B. The appearances of the turnips and buck-wheat were so nearly uniform, I have not thought it necessary to notice the trifing variations between them, which cuuld not have been done without entering into a minute detail, equally tedious and uninteresting.

Though nothing decisive can probably be drawn from these two sets of experiments respecting the advantages or disadvantages of salt as a manure, on such a soil as I have described, because other manures of acknowledged efficacy shared the same fate with the salt; yet this inference, however, may he drawn from them (and that not an unimportant one), namely, that a due texture and consistence in the soil is as necessary to the existence and health of vegetables, as the pabulum they are sustained by ; and this appears evidently by the superiority, such as it was, of those plants where the manure contributed in any degree to improve that texture and consistence.

Adjoining to the place where these experiments were tricd is a field, which fully confirms this observation. Within these few years, a great part of it was in a state of uncultivated nature, equally barren as the spot I bave been speaking of ; it is, however, now bronght into cultivation, and into a decent state of fertility, chiefly from its texture having been improved by a thick coating of marly clay.

In trying the effects of salt, when mixed with the frod of animals, I have made no experiments on shecp, as I did not apprehend that a few limited experiments would either 
throw new light upon a subject which has already been sufficiently discussed, as applied to those animals, or furnish the public with facts of which it is not already in possession. My experiments have therefore been confined to hogs and cows.

On July 23d, 1804, three hogs of the same litter, about eight months old, were put up to fatten. Their respective weights were as follow:

$$
\begin{array}{r}
\text { No. 1. } 44 \text { lbs. } \\
\text { 2. } 47 \mathrm{lbs} . \\
\text { 3. } 40 \text { lbs. }
\end{array}
$$

From the 23d of July till the 7th of August they were fed with barley-meal mixed up with water; during which time they consumed three bushels and a half of barley, and gained in weight as follows :

No. 1. $12 \mathrm{lbs}$.

2. 10 lbs.

3. 5 lbs.

From the $3 \mathrm{~d}$ of August to the 21st, they had salt mixed with their food, of which they consumed one quarter of a pound per day. The food consumed was four bushels : they had gained upon the last weighing as under:

$$
\begin{aligned}
& \text { No. 1. } 18 \mathrm{lbs} \text {. } \\
& \text { 2. } 22 \mathrm{lbs} . \\
& \text { 3. } 14 \mathrm{lbs} \text {. }
\end{aligned}
$$

From the 21st of August to the $3 \mathrm{~d}$ of September the salt was discontinued, in which time they ate four bushels and a half of barley-meal, and their increase of weight was,

$$
\begin{aligned}
& \text { No. 1. } 24 \mathrm{lbs} \text {. } \\
& \text { 2. } 21 \mathrm{lbs} \text {. } \\
& \text { 3. } 21 \mathrm{lbs} \text {. }
\end{aligned}
$$

From the 3d of September to the 17th they had salt as before, and their consumption of food was the same as during the last fortnight, namely, four bushels and a half of barley-meal. Their gain of weight was,

$$
\begin{array}{r}
\text { No. 1. } 31 \mathrm{lbs} \text {. } \\
\text { 2. } 19 \mathrm{lbs} . \\
\text { 3. } 19 \mathrm{lbs} \text {. }
\end{array}
$$

They were then slaughtered.

It did not appear that the salt had any operation either in promoting thirst or stimulating their appetites, the consumption of food being nearly the same whether salted or not; neither does it appear that the salt had any influence on their fattening; perhaps the quantity allowed them was too little; and yet $I$ should think not, as there was enough 
to make their whole mass of food sufficiently savoury to the human taste.

In trying this experiment it will be observed, that I did not confine one parcel of hogs to salt, and another to unsalted food. This mode of trying experiments is always uncertain, as there will be frequently particular habits and tendencies in the individual animals which will vary the results, and prevent their being uniform. The fairest way, and that which is the least liable to error, is to compare each animal with himself, by feeding him at one period with one kind of food, and then, for an equal period, with another. If this principle which I have proceeded upon be right, there is nothing in these experiments to encourage the practice of administering salt to hogs with a view at lcast to increase their tendency to fatten; how far it may contribute to keep them in health is a different question, and on which years of experience may probably be necessary to decide. Now I am upon this subject I shall nicntion (though totally foreign from the object of this essay), that for most internal disorders which hogs are liable to, all of which may be supposed to be more or les $\hat{n}$ accompanied with fever, I find 110 remedy so efficacious as antimony. This mineral is said to have obtained its name from the head of a religious house, who had administered it with success to his hogs, giving it in such quantities to the monks of his order as to poison them: a circumstance which probably brought it at the time into disrepute as a medicine, as well for the real as the metaphorical higs, The anecdote, however, whether true or false, induced me some years ago to try it upon hogs; and I can safely aver that, when taken in time, there are few internal diseases which hogs are subject to that will not yicld to antimony in some form or other. That form which I prefer is emetio tartar, as lying in small compass. I give it in doses from five to forty or fffy grains, according to the age and strength of my patient; and I believe still larger doses might be given with equal safety, as I do not recollect a single instance in which the animal seemed to suffer from being over-dosed.

To persons who have not tried the effects of antimony on the brute creation, the quantity I give may seem to be strangely disproportionate to the bulk of the hog compared with that of a man; but the experience of many years has convinced me that there is no analogy (I mean as far as quantity is concerned) in the effects of antimony on the human constitution. and on the constitution of inferior animals. 
On the 9th of October 1804, my experiments on cows commenced. On that day two Welch heifers, one of which had calved about five months, the other three, were confined to the house, and fed with hay for the space of one fortnight. The hay they consumed during that time was four hundred weight nineteen pounds, and the milk they produced was thirty-six gallons three quarts. They had then, for the next fortnight, salt mixed with their hay, the hav being first slightly noistened with water, and the salt sprinkled over it; in which time they consumed four hundred weight forty-two pounds of hay, and seven pounds of salt. The milk produced was thirty-seven gallons. For the next fortnight, namely, from the sixth to the twentieth of November, the salt was omitted, and their food was four hundred weight and one quarter of hay, and two hundred weight and a half of cabbages. The produce of milk in that space of time was fifty-four gallons three quarts. From the twentieth of November their food was the same as before, with the addition of half a pound of salt per day. The produce of milk was fifty-seven gallons one quart.

It will be recollected, that salt seemed to have no tendency to promote thirst or to increase appetite in the hogs; yet on the cows its effects in one respect were yery perceptible, for during the period they had salt they drank three gallons a day each more than at other times.

Salt may possibly promote digestion, notwithstanding its antiseptic quality, by stimulating the salival glands and the glands yielding the gastric juice, and by inducing an increased discharge of their respective fluids, so necessary to the solubility of the different substances received into the stomach before they can be admitted into the lacteals.

Though there may be nothing in the foregoing experiments to lead us to suppose that salt has any otherwise a tendency to promote a disposition in animals to fatten than as it may contribute to their health by aiding their digestion, yet it is probable that, when administered to animals yielding milk, it may contribute in some small degree to increase that secretion; and this it may do by promoting thirst, which induces the animal to drink copiously; in consequence of which the secretion of milk, as well as all other secretions of the fluids, may be augmented. Perhaps also it may have a stimulating influence on the lacteals themselves.

And yet, after all, admitting these experiments to prove that salt increases in some small degree the production of milk, 
millk, - when that increased quantity is balanced against the price of the salt, the dairy-man will find himself no gainer.

Though there does not seem any thing in these experiments, either with hogs or cows, to encourage the practice of giving salt to animals with a view to increase their disposition to fatten, yet it would be temerity to affirm that it is entirely useless. From the avidity with which most if not all kinds of graminivorous animals, whether in a state of domestication or otherwise, are known to eat salt whenever it comes in their way, it is reasonable to conclude that the propensity has not been implanted in them in vain. But from whatever cause its salutary effects may be supposed to proceed, whether (as was hinted at before) from its promoting digestion and an increased secretion of fluids, or from any other action it may have on the animal oconomy, it must be left to an experimenter more successful than I have been, to ascertain.

VI. On the Analysis of Soils, as connected with their Improvernent. By Humphrey Davy, Esq. F.R.S. Professor of Chemistry to the Board of Agriculture and to the Royal Institution*.

\section{Utility of Investigation relating to the Analysis of Soils.}

$\mathrm{I}$

$\Gamma_{\mathrm{HE}}$ methods of improving lands are immediately connected with the knowledge of the chemical nature of soils, and experiments on their composition appear capable of many useful applications.

The importance of this subject has been already felt by some very able cultivators of science; many useful facts and observations with regard to it have been furnished by Mr. Young ; it has been examined by Lord Dundonald, in his treatise on the connexion of chemistry with agriculture, and by Mr. Kirwan in bis excellent essay on manures : but the inguiry is still far from being exhausted, and new methods of elucidating it are almost continually offered, in consequeace of the rapid progress of chemical discovery:

In the following pages $I$ shall have the honour of laying before the Board an account of those methods of analysing soils which appear most precise and simple, and most likely to be useful to the practical farmer; they are founded partly upon the labours of the gentlemen whose names have

* From Communications to the Board of Agriculture. 